\title{
PROFESSOR F. ALTON WADE'S ANTARCTIC GLACIOLOGICAL RESEARCHES
}

By the Reverend W. L. S. FLeming

On 7 May 1939 Professor F. Alton Wade, Chief Geologist of Admiral Byrd's Third Antarctic Expedition, which came to be known as the U.S. Antarctic Service Expedition 1939-4I, wrote a letter in the course of which he expressed the view that the efforts of the various expeditions to the polar regions should be more closely coordinated than they had been in the past. He therefore asked me if the Association for the Study of Snow and Ice would be prepared to make suggestions for his glaciological programme, including methods, technique and apparatus. The Committee of the Association readily agreed and set aside a time for discussing this at the Association's meeting on 12 July 1939.

A summary of the discussion was published in Vol. I, No. 3, of Papers and Discussions and a fuller account was made available to those interested.

Our discussion, in which over fourteen members took part, covered a far wider range of research than a single expedition could undertake, the purpose being to make suggestions from which Wade might select. The following subjects were included in the report submitted : seismic sounding, rate of movement in the Ross Shelf Ice, mapping of the Ross Shelf Ice edge, physical properties of the water beneath the ice, the growth of the shelf ice from below, the gradient of the shelf surface, evidence of former glaciation and the study of any exhumed cirques, the classification of glacier and ice masses, the examination of melted snow and ice for cosmic dust, the collection of snow and ice samples for estimation of heavy water, measurements of glacier temperature and of glacier flow, the growth of ice crystals with vertical depth, banding and a general comparison between ice in Antarctic and temperate glaciers.

In spite of the short time between our meeting and the departure of the expedition, Wade was able to write in his paper ${ }^{1}$ ". . . our final plans were based for the most part upon the suggestions of our British colleagues." Apart therefore from the welcome opportunity of discussing profitable fields for future Antarctic glaciological research, we can have the satisfaction of knowing that our deliberations seem to have been of some value and stimulus.

Unfortunately however the work which Wade had so carefully planned had to be curtailed for two reasons. First, the failure of the snow cruiser and, second, the unexpectedly early termination of the expedition on account of the war.

The research was therefore confined to the expedition's West Base at the Bay of Whales during the winter months and was undertaken principally by F. Alton Wade and Laurence Warner. The investigations all concerned ice studies on the Rose Shelf and can be grouped under five headings :

1. Density increase in the upper layers of shelf ice. (Fuller details will be found on pp. 162-66 of the paper cited above.)

A pit was dug in the floor of the ice laboratory at West Base. 'The shaft head measured $2 \times 2$ metres, its depth 7 metres. An auxiliary pit 2 metres deep was made 200 metres to

1 The Physical Aspects of the Ross Shelf Ice. Proc. Am. Phil. Soc. Vol. 89, No. 1, 1945, pp. 160-73. 
the west. The profiles of the uppermost 2 metres and the densities of the upper layers in both pits were compared.

The firn of the shelf ice is definitely stratified. The different strata vary considerably in thickness and in texture. The thickness of a stratum varies considerably in short horizontal distances. Thin beds of true ice occur at irregular intervals. None of the ice bands are over 2 centimetres thick except locally, where they were noted in rare instances to be as much as 4 centimetres thick. The increase in density with depth was apparent during the excavation operations. The upper layers were easily sawed and removed in blocks, while the firn

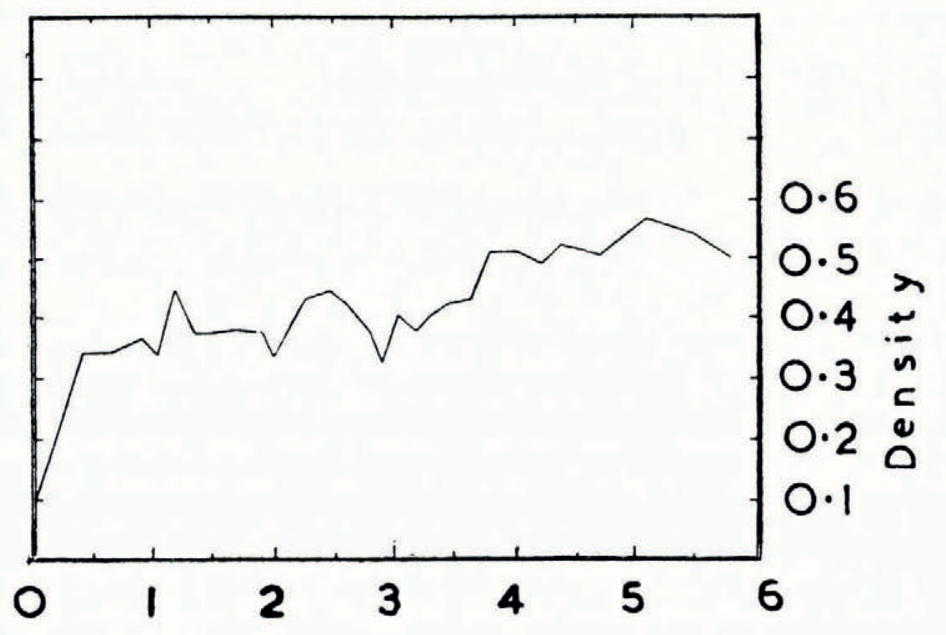

Depth in Metres

Fig. 5. Variations of firn density with depth below the 5 -metre level was sawed with great difficulty and finally it was necessary to resort to blasting.

In order to measure densities at different levels a snow sampler was used. This apparatus was designed so that each sample container could be detached, sealed with a cap at either end and then weighed. The sampler was successfully used for densities up to 0.5 , but for the lower layers carefully measured blocks of either 500 cubic centimetres or 1000 cubic centimetres were cut and weighed. For thin layers of ice or wind crust, small pieces were weighed in air and again in alkazine and their densities were determined by the standard method.

The increase in density with depth is indicated in Fig. 5, above. The increase is general but not regular. Certain anomalies appear in strata composed of coarse grained, loosely adherent crystals. Wade decided that the primary cause of density increase is the packing of the crystal grains. This process is assisted in the early stages of firnification by the removal of small crystal projections by sublimation and the surface migration of water molecules. In glacier ice the process is assisted by the crystallization involved in flow by plastic deformation. He ascribed the continued compaction in the lower layers to the increasing weight of the superincumbent layers with depth.

The rate of settling in the firn was determined by three compression meters similar to those used by Moss. ${ }^{1}$ The results gave much lower values than the $2 \cdot 3 \times \mathrm{ro}^{-3}$ centimetres per centimetre per day of Hughes and Seligman at a depth of 2 metres in a temperate glacier.

${ }^{1}$ Moss, R. Geog. Fourn. Vol. c2, 1938, p. 220. 
The fact that the settling varies with the temperature is noteworthy and even when the temperature is continually below freezing it is possible that the rate may be a function of the temperature.

\section{Size and orientation of the ice crystals at various depths}

Warner, who undertook this work, was unsuccessful in indurating porous ice with isobutyl methacrylate solution in chloroform and immersed his samples in a beaker of water cooled to freezing point, removed them, and exposed them to the air at $-30^{\circ} \mathrm{C}$. He maintained that the water had little corrosive effect on the ice and that he could distinguish the new interstitial ice by its rhombic form and by the fact that it showed anhedral boundaries to the ice grains. The sample was then ground to half a millimetre thickness. (The exact details of method and equipment are given in the paper cited, pp. 172-73.)

Unfortunately Warner was abliged to restrict his investigations to the uppermost 2 metres of the firn; the ice bands were studied down to 5 metres. He concluded that there is a definite increase in grain size with depth, but with notable exceptions, and added that it was safe to say there was no definite orientation of the ice crystals, at least to the depth investigated. This differs from the findings of Perutz and Seligman who reported definite crystallographic orientation at shallow depths in the firn of the Great Aletsch Glacier.

Wade draws the conclusion that melt water and recrystallisation, which are absent in the Ross Shelf Ice, are necessary for crystal orientation to take place. The microscopic investigations also showed a diminution in the size of the intercommunicating channels with depth and an increase in the number of fractures per grain. No border zones indicating crystal growth were noted. These observations all point toward mechanical settling and compaction as the primary factors responsible for the increase of density with depth.

The section of the Ross Shelf Ice to which these investigations were confined is freefloating. It should therefore move forward as a unit with no differential horizontal movement in the various layers. In order to determine whether or not this was so, vertical rows of closely spaced pins were inserted in the walls of the shaft to its full depth. The positions of these pins were checked against a plumb line at intervals over a period of three months and no differential movement was indicated.

\section{Banding in the firn}

Two distinct types of ice bands are common in the shelf ice: (i) Clear ice bands, and (ii) fine-grained closely packed bands. In some cases the clear ice bands are continuous over wide areas and follow a fairly regular plane surface; in others they are very irregular and extend for varying distances. Single layers often divide and form a series of two or more closely spaced layers separated by thin bands of clear ice grains. These divided layers are sometimes found in the form of lenses $4^{-6}$ inches wide and are often orientated at angles up to 45 degrees from the horizontal. The clear ice layer varies in thickness from a fraction of a millimetre to 3 centimetres.

From the surface to a depth of 2 metres the clear ice layers are quite distinct and easilv distinguishable from the overlying and underlaying firn layers. In the denser zones at lower depths the ice bands lose their individuality and, although they can still be identified at a depth of 6 metres, they are no longer separated from the dense firn by sharp stratification planes. Often the "blue-ice" characteristics are destroyed and a grainy texture is developed

The second type of band closely resembles the "wind crust" as described and explaine: 
by Seligman. ${ }^{1}$ These bands are generally continuous over wide areas. They average in thickness between $I$ and 3 millimetres. The formation of this type of band is often observed on the surface throughout the year. In some cases a fine laminated structure is developed. The "wind crust" bands are easily identifiable in the upper zones by this laminated structure. These bands also lose their individuality with increasing depth and appear to be partially assimilated by the surrounding dense firn.

While the origin of the fine-grained, close-packed bands may be ascribed with some confidence to wind crust, it is not so easy to understand how the clear bands form. At first they were thought to be due to melt water when the air temperature was near or above freezing point, but as crust formation was not observed under these conditions and the bands were found in layers deposited during the winter, this seemed to be ruled out. Dr. Siple and Professor Wade are of the opinion, from their observation of recently formed ice crusts, that these bands originate as crusts when low clouds containing super-cooled moisture come in contact with the surface.

A serious attempt was made to establish a seasonal differentiation between various strata and bands in the firn. Ahlmann ${ }^{2}$ was able to distinguish a boundary separating the accumulations of two years on Isachsen's Plateau, Spitsbergen. No such layers could be identified in the Ross Shelf Ice even after the annual accumulation was known.

\section{Change in the snow surface level}

In order to determine accurately the change in the snow surface level during the year, eight gauges, similar to those used by Moss in North-East Land, were installed in the vicinity of West Base. (For details of method see paper cited, p. r67.) Readings were taken over a period of just under a year and the result is shown graphically in Fig. 6, p. 27, which indicates an average rise of 84 centimetres in $34^{8}$ days.

The only other accurate measurements of the absolute magnitude of the annual accumulation on the Barrier surface are those made by Mackintosh, when his party discovered Captain Scott's Depot six and a half years after it was laid. This gave an annual increment of 38 centimetres. ${ }^{3}$ This was less than half the value obtained at West Base. It is probable that more snow was lost through drifting in that area, which is quite near the mountains, than near the Bay of Whales.

Wade considers that the greater part of the annual accumulation is caused by drift snow. No attempt was made to estimate the proportions of drift snow, new snow and hoar frost. Wade considers that ablation is responsible for a loss of not more than 2 centimetres in the year.

There is undoubtedly a small amount of settling in the layers above the gauge bases, since surface layers often have densities as low as 0.1 when deposited, but these soon become more dense in a few days through settling. The deflation process is by far the most important. The surface rises and falls at the will of the wind. Much snow is transported in and much is removed. Often during the first part of a blizzard much drift would be deposited, and during the latter part of the same storm a considerable proportion of the new drift

${ }^{1}$ Seligman, G. Snow Structure and Ski Fields. London: Macmillan, 1936, pp. 163-82.

2 Ahlmann, H. W. Scientific results of the Norwegian-Swedish Spitsbergen Expedition in 1934. Geog. Annaler, Vol. 17, 1935, pp. 34-37.

${ }^{3}$ Wright, C. S. and Priestley, R. E. Scient. Reports British (Terra Nova) Antarctic Expedition, 1910I913, Glaciology, London, 1922, p. 162. 
ANTARCTIC GLACIOLOGICAL RESEARCHES

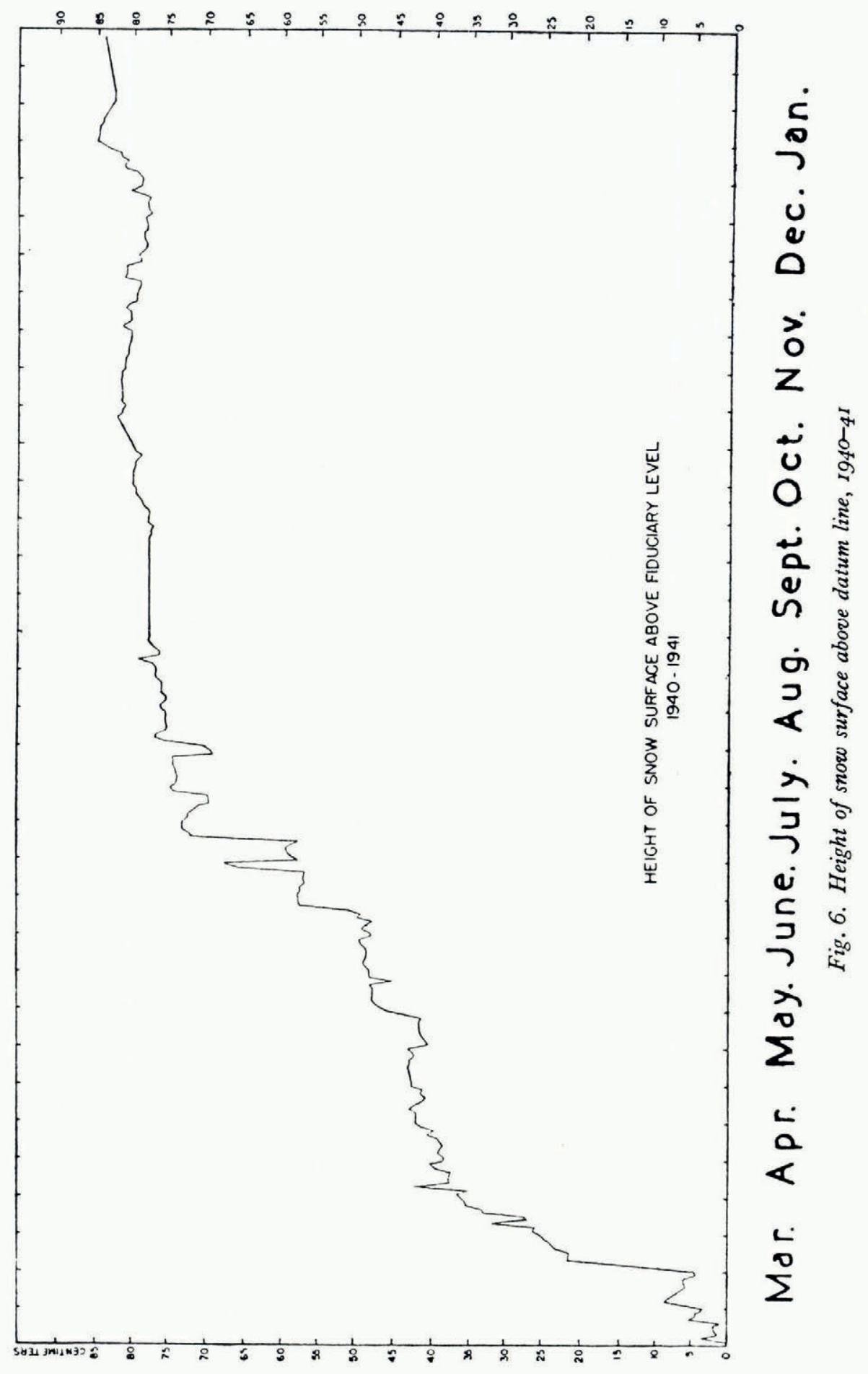




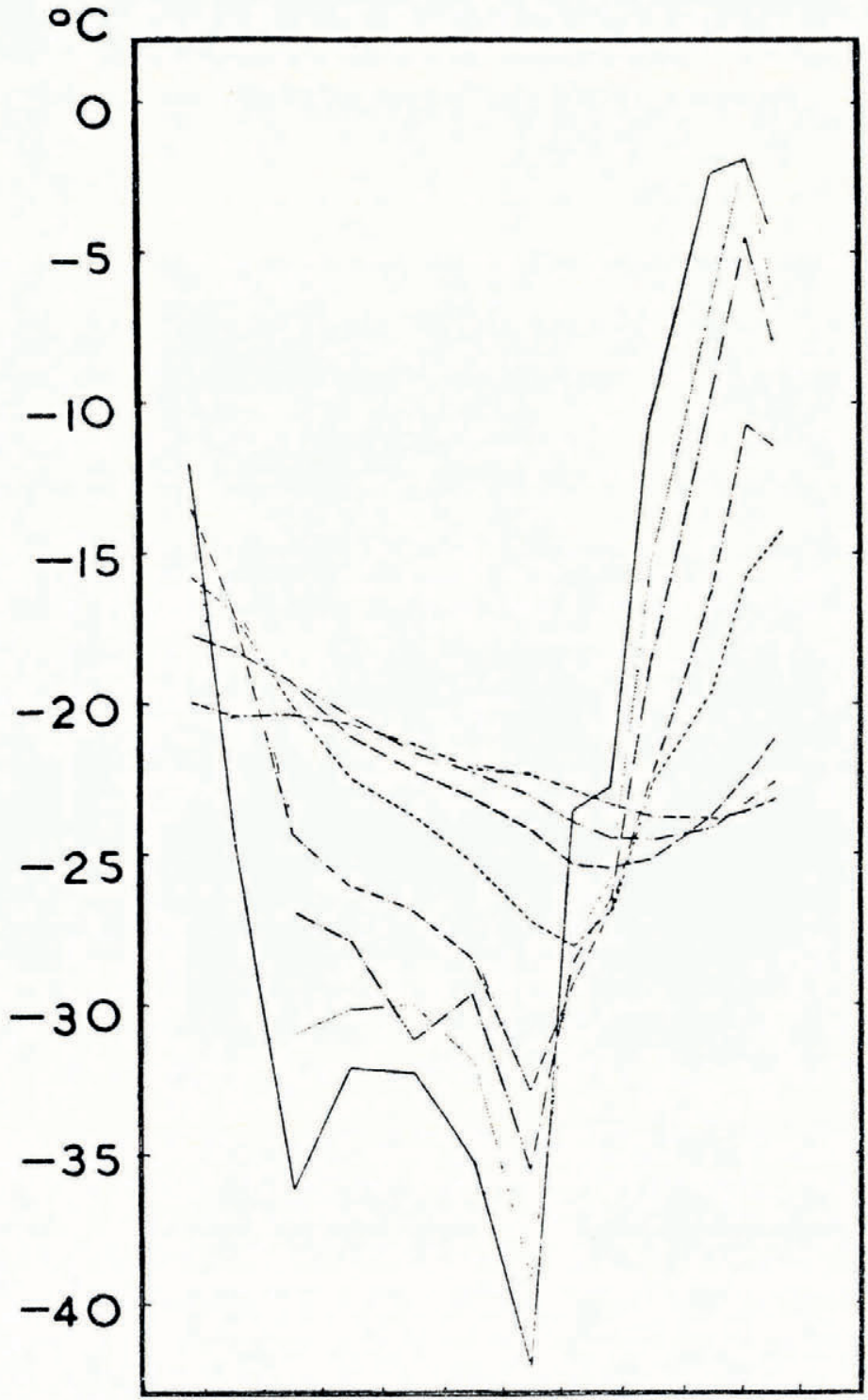

M. A.M. J. J. A. S. O. N. D. J.

$1940-1941$

Surface
0.25 metres beneath surface

Fig. 7. Temperatures at different depths beneath surface, 1940-4I 
would be removed. Some winds are depositional, others purely erosional. However, preliminary studies of wind directions and velocities versus surface changes yielded no correlative evidence. The character of the surface must also be considered. If it is composed of loose, unconsolidated grains, comparatively light winds might remove much of it, whereas if it is tightly packed or crusty in character, the same winds have little effect on it.

Attempts to correlate the stratification of the increment at different levels proved negative. The strata themselves and the ice bands are too local in character. Wade formed the opinion however that wind crusts could be used as reference levels.

Summations of the positive and negative increments throughout the year brought to light an interesting fact. There was an approximate total increase of 170 centimetres in elevation and a decrease of 85 centimetres. In other words, for each 2 centimetres of snow added by deposition during a year, I centimetre was lost through erosional processes.

\section{Temperatures at various depths in the firn}

This part of the investigation was of particular interest since no systematic measurements of the subsurface temperatures had ever been previously made in shelf ice. A series of resistance bulb thermometers, or thermohms, was connected to a multiple switch in the now stationary snow cruiser and this in turn to a modified Wheatstone bridge so calibrated that temperatures could be read off directly.

A hole was drilled in the snow below the cruiser for each thermohm and subsequently filled in after the thermohm was in place. Thermohms were installed at the following depths in metres: $0.25,0.50,1,2,3,4,5,10,15,20,25,30,36$ and 41 . An additional thermohm was installed approximately to centimetres above the surface. Observations were begun on 5 thermohms in the middle of March 1940, on the others a month later, and were continued until 20 January 194I. The results are expressed graphically in Fig. 7, p. 28.

It will be noted that the winter cold wave penetrates to a depth of at least 5 metres and possibly several metres farther. There are no significant changes in the temperatures of the firn at depths of 15 metres and more. The temperatures of these lower zones remain constant at approximately the same temperature as the average annual temperature of the air. For the interval of Wade's stay at West Base this value was $-23.7^{\circ} \mathrm{C}$. This substantiates the ideas regarding glacier temperatures advanced by Chamberlain. ${ }^{1}$

The thermohms at depths of 36 and $4 \mathrm{I}$ metres were below sea-level. There is a slight rise in temperature with depth below 15 metres, and it is probable that this is due to the effect of the warmer sea water below the shelf ice.

The task of interpreting the subsurface temperatures and their variations was only begun. It is hoped that further study will bring to light more interesting facts relative to the mechanics of shelf ice.

Wade attributes the origin of the Ross Shelf to the confluence of piedmont glaciers, extended ice caps, and sea ice. To-day it is largely kept in existence by annual accretion at the surface. When the ice is free-floating it is composed of a series of layers of firn which vary in thickness and are separated by layers of ice or wind crust. Near its landward and island borders the lower zones are probably in part composed of hard glacier ice, but when the shelf is floating Wade found a constant loss in the lower layers through melting, and the

\footnotetext{
${ }^{1}$ Chamberlain, T. C. A contribution to the theory of glacier motion. Univ. Chicago Decennial Publ., ser. 1, Vol. 9, 1904, pp. 196-200.
} 
composition of the shelf gradually changes until it is composed only of depositional strata. The yearly increment added to the upper surface must approximately equal the loss through melting in the lower layers, since no pronounced variations over a period of years in elevation of the Ross Shelf Ice have been reported by observers. However, no accurate measurements have yet been made.

This concludes Professor Alton Wade's results. I have kept rather rigidly to his own words and interpretations. The work he and his colleagues undertook constitutes a valuable addition to our knowledge of shelf ice, and we may be grateful that he had chosen for research investigations of a basic character. The results are of all the greater interest in as much as the physical aspects of the Ross Shelf Ice, which do not involve the influences of differential movement or of melt water, provide a useful standard of reference for comparison with other glacial forms.

Further microscopic work and observations at greater depths may be expected to yield an even fuller understanding of the process of firnification in shelf ice at temperatures below freezing point.

\section{DISCUSSION}

Mr. A. R. GLen: We are honoured in having with us to-day Professor Olaf Holtedahl of Oslo University and President of the Norwegian Academy of Sciences, who might like to say a few words.

Professor HolTedahL: I am very glad to be present this afternoon at a meeting of this Society which I hope you will be able to develop. There is a need for a Society of this sort in which all nations can join, and which can produce a journal of glaciology. I am not a glaciologist although I am very interested in this subject, but more from the physicist's and geologist's point of view.

Mr. A. R. GLEN : No one is more qualified than Mr. Seligman to follow up Mr. Fleming's paper and I should like to call on him.

Mr. G. Seligman: I would like to say first of all however that I have never heard a more lucid exposition of a subject than Mr. Fleming has given us. I would also like to take this opportunity of congratulating Professor Wade on the work of this expedition. I am interested in the theory that ice bands, forming under conditions where ordinary melting does not take place, are the result of super-cooled moisture coming in contact with the snow. I would like a little more evidence of the conditions because my natural belief would be that super-cooled droplets would freeze into tiny little ice crystals which in aggregate would not look like ice but rather more like firn, owing to the numerous crystalline boundaries. If however it is correct it solves something that often puzzled us. Another point of interest is that the firn crystals in the upper layers of the shelf ice were not oriented. It is accepted that as snow falls the crystals orient themselves in haphazard manner, but in a temperate glacier Dr. Perutz came to the conclusion that many of them melt and refreeze with their optical axes perpendicular to the incidence of the cold wave, thus ranging themselves in a single direction. The fact that little or no melting takes place in this region would deter this re-orientation from taking place. As President of this Society I, too, would like to say how warmly we welcome Professor Holtedahl here this afternoon.

Mr. A. R. Glen : Perhaps Dr. Perutz would like to answer Mr. Seligman's suggestions.

Dr. M. F. Perutz: The first thing that strikes one about Professor Wade's expedition is the great improvement in technique. If you look at the picture in our Jungfraujoch publication of Dr. Hughes measuring temperatures by carrying round a galvanometer and all the thermo-couples and compare it with Professor Wade's streamlined apparatus, you can see great progress. In the preparation of thin ice sections they have also done better than we did. One result that interests me is the absence of preferred crystal orientation in the upper firn layers. At the Jungfraujoch our 
first idea was that crystal orientation was due to flow, but this was later discredited and it was decided that it must be due to melting and refreezing as Mr. Seligman has explained. As regards firnification, Winterhalter, a Swiss crystallographer, found that the rounding off of a snow crystal goes on even when the vapour phase is excluded. He immersed snow flakes in liquid paraffin and observed that the snow crystals soon became rounded off. Since sublimation would not have taken place under these conditions, Winterhalter came to the conclusion that the rounding off of snow crystals was due to the migration of water molecules over the crystal surface. Such surface migration therefore constitutes at least part of the process which is known as firnification.

Mr. A. R. GLeN: Would Dr. Odell like to contribute?

Dr. N. E. Odell : I would like first to bear out what Mr. Seligman has said about Mr. Fleming's lucid report. Much of this work is rather outside my province. One thing in particular, though, in which I am interested is this question of ice-banding. One would like to see the written results when they are available, with diagrams and illustrations, as I cannot quite gather what the distribution of these ice bands and lenses is in nature. Is the lenticular structure to be found in the fine banding or the thick banding?

Mr. W. L. S. Fleming: In the thin, clear bands.

Dr. N. E. ODELL: Did Mr. Seligman find much lenticular structure during his Jungfraujoch observations?

Mr. G. Seligman: We found a certain number and of very much greater thickness than has been mentioned here, but they were rather the exception than the rule.

Dr. N. E. Odell: I have myself seen very little lenticular structure of this kind and wonder how it was orientated and disposed.

Mr. G. Seligman: The shape of the lenticular bands lends a certain amount of support to the suggestion that they are due to the freezing of fog or water vapour. In that case one would expect maximum concentration in the centre and a thinning away towards the margins.

Dr. N. E. ODELL: There was no suggestion that the lenticular structure might be disccvered to be a form of foliation of the ice due to pressure and shear?

Mr. G. Seligman : None at all as they were surface phenomena. We found these bands became less distinct lower down and ultimately they disappeared, a fact which was first noticed, I believe, by Whymper; it has been noted by every investigator since and it must be universal.

Dr. M. F. Perutz: 'There is an old photograph of Drygalski's showing banding in the Ross Shelf Ice where the banded structure also became less and less distinct, but he attributed this to the glacier movement.

Mr. A. R. GLEN : If there are no more questions or comments, in bringing the meeting to a close I would like to say how gratifying it is that Professor Wade found the programme compiled by this Society to be of material benefit to him. This opens a road in the future which the activities of the Society could develop with profit, both to ourselves and to similar expeditions which we hope will soon go out again. We can now have confidence whenever we prepare such programmes
in the future.

I might mention that the lenticulated bands were also found in North-East Land, particularly near the surface, and we also found that the sharp definition seemed to disappear with depth. Increase of grain size was also noticeable. Professor Wade's results seem to be consistent with what might be expected from climatological conditions existing in the Antarctic and constitute a most valuable comparison with the work that has already been carried out on temperate glaciers.

I would add to what several speakers have said this evening in paying tribute to the very clear and lucid way in which Mr. Fleming has given his paper. It has been a joy to listen, for the paper has suggested so much of value to our future plans. That concludes our business to-day and I now
call this meeting closed. 